\title{
3D DIC-assisted residual stress measurement in 316 LVM steel processed by HE and HPT
}

\author{
Tomasz Brynk $^{1}\left[\right.$ - Agnieszka Teresa Krawczyńska ${ }^{1} \cdot$ Daria Setman $^{2} \cdot$ Zbigniew Pakieła $^{1}$
}

Received: 1 March 2020 / Revised: 25 April 2020 / Accepted: 21 May 2020 / Published online: 1 June 2020

(c) The Author(s) 2020

\begin{abstract}
A method has been developed for determining residual stress based on displacement fields near drilled holes analyzed using 3D digital image correlation. Finite element modeling was used to determine corrections for analytical equations describing displacement fields near the blind holes, which made it possible to determine the residual stress distribution over a wide range of hole depth-to-hole diameter ratios and various areas of displacement field measurements using inverse method iterative calculations. The proposed method eliminates many drawbacks of traditional procedure based on strain gauges as hole eccentricity sensitivity and requirement of the relatively large span between holes. The method and testing setup, build-up of generally available components, were used to determine the residual stress distribution for $316 \mathrm{LVM}$ samples processed by two methods from the large deformation group: hydrostatic extrusion (HE) and high-pressure torsion (HPT), by drilling 1.75 and 0.58 -mm-diameter blind holes, respectively. In the case of the measurements performed on the surface of a HEprocessed $16 \mathrm{~mm}$ bar cut along its diameter, a gradual change was revealed-from a compressive to a tensile residual stress distribution (from - $300 \mathrm{MPa}$ in the center to $400 \mathrm{MPa}$ in $4 \mathrm{~mm}$ distance from the edge) in the longitudinal direction, with near-zero values in the radial direction. Moreover, the method was also adapted to perform measurements on the outside surface of the bar, which gave results consistent with those taken along the radius profile ( 600 MPa longitudinal stress). Measurements on the top surface of a cylinder $10 \mathrm{~mm}$ in diameter and $1 \mathrm{~mm}$ high processed by HPT showed a high compressive residual stress in the center and a dominant shear component for the holes drilled at different distances from the center.
\end{abstract}

Keywords Residual stress $\cdot 3 \mathrm{D}$ digital image correlation $\cdot$ Hydrostatic extrusion $\cdot$ High-pressure torsion $\cdot$ Severe plastic deformation $\cdot$ Austenitic steel

\section{Introduction}

Residual stress may be introduced to materials during both production and service. The presence of residual stress may have a positive or negative influence on a material's properties, depending on their distribution and magnitude. Knowledge of residual stresses is crucial in investigations related to fatigue life, corrosion resistance and dimensional stability [1]. Therefore, there is a need for accurate methods of measuring the development of residual stress, since the currently

Tomasz Brynk

tomasz.brynk@pw.edu.pl

1 Faculty of Materials Science and Engineering, Warsaw University of Technology, Woloska 141, 02-507 Warsaw, Poland

2 Faculty of Physics, University of Vienna, Boltzmanngasse 5, 1090 Vienna, Austria available methods feature certain, especially in respect of materials usually available in small volumes or having a complex shape, of which materials processed by Severe Plastic Deformation (SPD) methods are a prominent example [2-6]. SPD makes it possible to change the microstructure from micrograined to ultrafine or nanograined, resulting in materials of extremely high strength, wear, and corrosion resistance. As one can imagine, during SPD, a high deformation is imposed, which generates a high residual stress that changes rapidly along the diameter or length of products. For this reason, there is a strong need to measure such stress, but it seems this issue has not been given enough attention, as the data available are scarce [7-9].

Ultra- and nanocrystalline materials in which grain refinement was achieved by means of SPD have been intensively investigated for over 30 years [2-6]. The two most popular methods of grain refinement by SPD are equal-channel angular pressing (ECAP) and HPT [5]. Theoretically, in these 
methods, the amount of strain accumulation is unlimited, since an unlimited number of passages of the billets through the angular channel are possible, or an unlimited number of rotations, while the shape of the billet remains almost unchanged.

In the case of HPT-processed materials, large gradients of strain are observed along the disks' radii $[6,10,11]$ due to an increase in the total accumulated strain together with the distance from the sample center. This method also introduces a large residual stresses [12] and cracks [6] in the material.

An interesting alternative to SPD methods is hydrostatic extrusion (HE). Unlike ECAP and HPT, the billet shape is not preserved during processing. In this method, the diameter of the billet is reduced, and so the accumulated total strain is limited. Nonetheless, the method is efficient and makes it possible to obtain materials whose mechanical properties are similar or even better than those resulting from other methods [6]. The large strains introduced in materials processed by HE, and their inhomogeneity, also result in a complex distribution of residual stress in a processed bar's cross section [8].

The most popular technique for determining residual stress is based on drilling a hole and measuring strain in the neighborhood of the hole using strain gauges (so-called Mathar's method) [13]. Hole drilling causes a local relaxation of stress and a deformation of the surrounding area. Information on the strain values provided by the strain gauge rosettes (with three or six elements) and the geometry of the hole make it possible to calculate residual stress components. The method is standardized [14], and there are commercially available devices and rosettes allowing residual stress measurements to be made. The main drawback of the method is the necessity of fixing the strain gauge rosettes and soldering electric connections, which is time-consuming and requires an experienced operator. Moreover, the calculation is based on only a few measurement points ( 3 or 6 , equal to the number of strain gauge elements used), and just a small eccentricity in the positioning of the rosettes in relation to the center of the hole may result in a large measurement error. Another restriction of the method is the limited choice of the hole diameters and geometries defined by producers of the rosettes, and the requirement of having a flat surface.

To overcome these problems, a 3D DIC [15] method may be applied instead of strain gauges. DIC is a promising tool in experiments related to hole drilling experiments aimed at delivering residual stress because sample preparation is relatively easy, measurements need not be taken only on a flat surface, and it features good tolerance to vibration in comparison with interferometry methods [16]. It results in a much larger number of displacement/strain data points available for residual stress calculations and allows these to be used in the inverse method, as presented in this paper.
This abundance of data is assumed to compensate generally lower resolution of DIC measurements in comparison to strain gauges, where only a few measurements positions are considered.

The use of 3D DIC with two cameras oriented at a certain angle to the region of interest is very convenient because it makes it possible to place a simple drilling device between the cameras, and eliminates the need to move the optical system out of the way during drilling, which improves the accuracy of the measurements and makes the testing setup less complicated and less expensive, although at the cost of a more complicated calibration procedure in comparison with 2D DIC [17].

With the above in mind, the presence of residual stress in materials processed by different large deformation methods, whether preserving or not preserving the original shape of the ingots, plays an important role in an understanding of their properties and when planning potential applications. There are many fields where nano- and ultrafine-grained materials may be used and where high fatigue resistance and strength is demanded, e.g., bioimplants [18] and fasteners in marine industries and off-shore cranes [19].

The implementation of traditional techniques of measuring residual stress designed primarily for microcrystalline materials is often problematic in the case of SPD-processed materials, due to the relatively small volume available for testing (the problem of fixing standard strain gauge rosettes in hole drilling-based methods), and the refined grains and texture resulting from large deformations (problems with accurately measuring changes in crystalline lattice parameters in methods based on X-ray diffraction). Therefore, a hole drilling-based method with optical measurements instead of strain gauges is expected to provide new knowledge concerning the properties of such materials. Having in mind the potential structural application of SPD-processed materials, the knowledge of residual stress distribution is important at the macroscale level. Nondestructive methods deliver results from small material volumes, usually. For example, X-ray diffraction method delivers information on residual stress from only 10-30 $\mu \mathrm{m}$ depth [20], and surface processing might have a large influence on measured values. Laborious work has to be done to extract values from larger depths by consecutive material removal by etching or electropolishing and repeating measurements. Neutron or synchrotron diffraction methods provide detailed information of residual stress tensor components from the depth up to $500 \mu \mathrm{m}$ [20]; however, their application is limited due to large costs of testing and a scarce number of facilities where tests could be made, especially with the latter method. Residual stress presence affects the results of instrumented indentation tests and may be calculated from unloading curves analyses; however, this method is also destined to microscale investigation. Another method from the nondestructive group, namely Barkhausen noise analysis (BNA) is limited only to 
ferromagnetic samples, so it cannot be applied to materials in question.

Although hole drilling-based procedures are established in the residual stress research field in the macro scale, there are still reported improvements introduced by the modification of calibration parameters, e.g., taking into account the magnitude of revealed stress [21] or drilling tool geometry [22]. In this paper, the general procedure of acquiring calibration parameters for blind holes presented in [23] has been enhanced, allowing to use of the data delivered from optical methods such as DIC or electronic speckle pattern interferometry (ESPI) delivered for arbitrary positions near drilled holes and for a wide range of hole geometries (depth-to-diameter ratios). The improved method of determining residual stress was applied in measuring samples of 316 LVM steel processed by HE and HPT, based on an analysis of the displacement field around drilled blind holes, using 3D DIC. The idea behind designing the testing setup was to obtain displacement fields without the need for a drilling tool and repositioning cameras between the removal of material and the image registration steps. Moreover, an attempt was made to enhance the applicability of the blind hole drilling-based method to include surfaces that are not flat.

\section{Materials and methods}

\subsection{Materials for testing}

Sandvik Bioline 316LVM, meaning a low-carbon, vacuummelted 316L-grade stainless steel, known also as UNS S31673 or ASTMF138, was used in this study. It was purchased in the form of annealed $50 \mathrm{~mm}$-diameter rods. The chemical composition of this steel is presented in Table 1.

The material was deformed by HE and HPT. The detailed information about these processes can be found elsewhere [24, 25]. In order to perform $\mathrm{HE}$, billets of $50 \mathrm{~mm}$ in diameter and $300 \mathrm{~mm}$ in length were cut from the rods. The HE process was performed at room temperature, as described in detail in the literature [19], in five passes so that a final diameter of $16 \mathrm{~mm}$ was reached, which corresponds to a total true strain of 2.3. The strain was calculated according to the equation $\varepsilon=2 \ln \left(d_{1} / d_{2}\right)$, where $d_{1}$ is the initial diameter and $d_{2}$ the final diameter. The microstructures obtained in this procedure were previously presented in [26]. They consist of nanotwins and shear bands in the cross sections. The microhardness reached an average value of $450 \mathrm{Hv} 0.2$. The $\mathrm{HE}$ was carried out at the Institute of High Pressure Physics of the Polish Academy of Sciences.
For the HPT, the material was cut into disks of $10 \mathrm{~mm}$ in diameter $0.8 \mathrm{~mm}$ thick. The disks were processed, similarly as with the HE, at room temperature. The disks were torsionally strained to 5 revolutions at a constant pressure of 6 $\mathrm{GPa}$. The strain was well defined as simple shear, $\gamma$, and was calculated according to the equation $\gamma=2 \pi \times r \times n / t$, where $r, n$ and $t$ are the distance from the torsion axes, the number of applied revolutions and the mean thickness of the sample, respectively. The equivalent strains $\varepsilon_{\text {eq }}=\gamma / \sqrt{3}$ calculated $5 \mathrm{~mm}$ from the central point of the sample were equal to 113. This process resulted in a refinement of the micrograins to nanograins of approximately $100 \mathrm{~nm}$ in diameter [27]. The microhardness reached an average value of $470 \mathrm{Hv} 0.2$. The HPT was performed at the Faculty of Physics at the University of Vienna.

The microstructures after HE and HPT were examined using a JEOL JEM 1200 EX transmission electron microscope (TEM) operated at $120 \mathrm{kV}$. The samples for TEM investigations were cut near the edge of cross sections, so that microscopy observations were performed $1.5 \mathrm{~mm}$ from the disk/rod edge. After cutting, three-millimeter in diameter disks were mechanically polished to reach the thickness of $100 \mu \mathrm{m}$ and afterward electropolished using Struers electrolyte A2. The microstructures are presented in Fig. 1. After HE, they consist of nanotwins and shear bands, as marked in Fig. 1a. Microstructures obtained in this procedure were previously presented in [26]. HPT resulted in a more significant grain refinement to nanograins of less than $100 \mathrm{~nm}$ in diameter, as showed in Fig. 1b [27].

\subsection{The methodology of residual stress determination}

The goal of the research was to determine the residual stress distribution in materials processed by SPD methods by utilizing displacement fields obtained from 3D DIC measurements near drilled blind holes. An improved setup for 3D DIC-assisted hole drilling was applied, as had been used previously in the preliminary tests presented in $[28,29]$ and whose final version is presented in Fig. 2. It consists of a frame, a horizontal translation table, two CCD cameras, a spindle, and a light source. The spindle was mounted to the vertically oriented translation table driven by a step motor. Before testing, the movement of the vertical translation table was calibrated by correlating its displacement with revolutions of the motor. The drilling process was controlled by positioning a step motor with an Arduino Uno microcontroller. Holes were drilled with 10,000 RPM. Preliminary
Table 1 Chemical composition (wt\%) of austenitic stainless steel 316LVM

\begin{tabular}{llllllllll}
\hline $\mathrm{C}$ & $\mathrm{Si}$ & $\mathrm{Mn}$ & $\mathrm{P}$ & $\mathrm{S}$ & $\mathrm{Cr}$ & $\mathrm{Ni}$ & $\mathrm{Mo}$ & $\mathrm{Cu}$ & $\mathrm{N}$ \\
\hline 0.025 & 0.6 & 1.7 & 0.025 & 0.003 & 17.5 & 13.5 & 2.8 & 0.1 & $<0.1$ \\
\hline
\end{tabular}


(a)

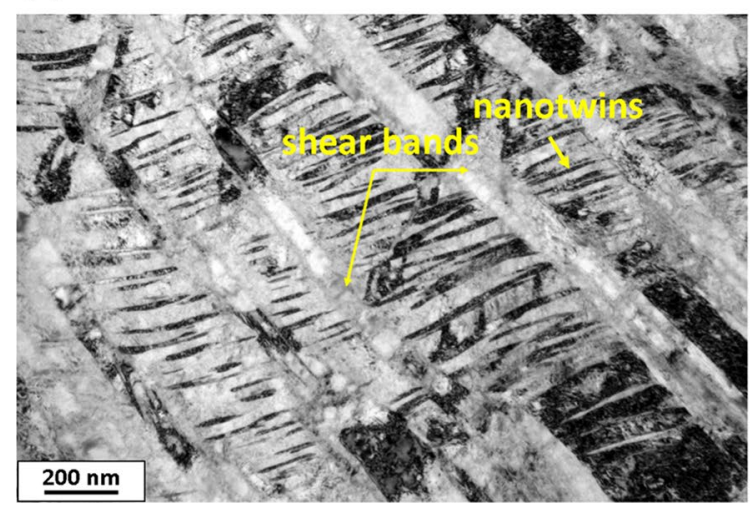

(b)

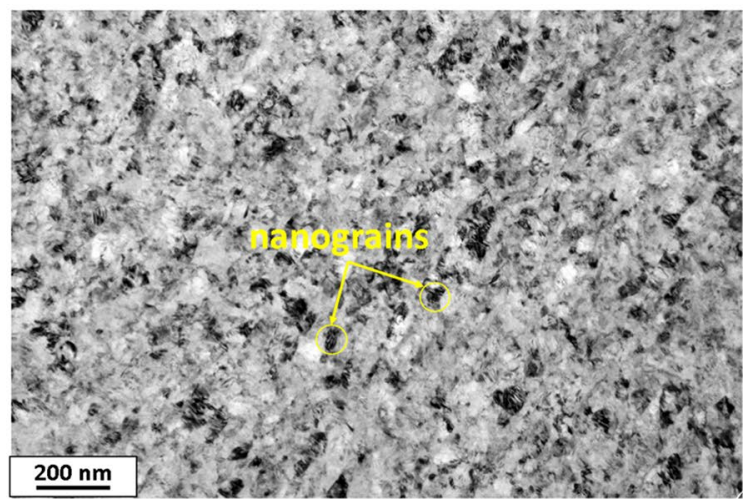

Fig. 1 Microstructures of austenitic stainless steel after a HE and b HPT—cross sections with marked nanotwins, nanograins, and shear bands

Fig. 2 Setup for residual stress measurements with hole drilling and 3D DIC

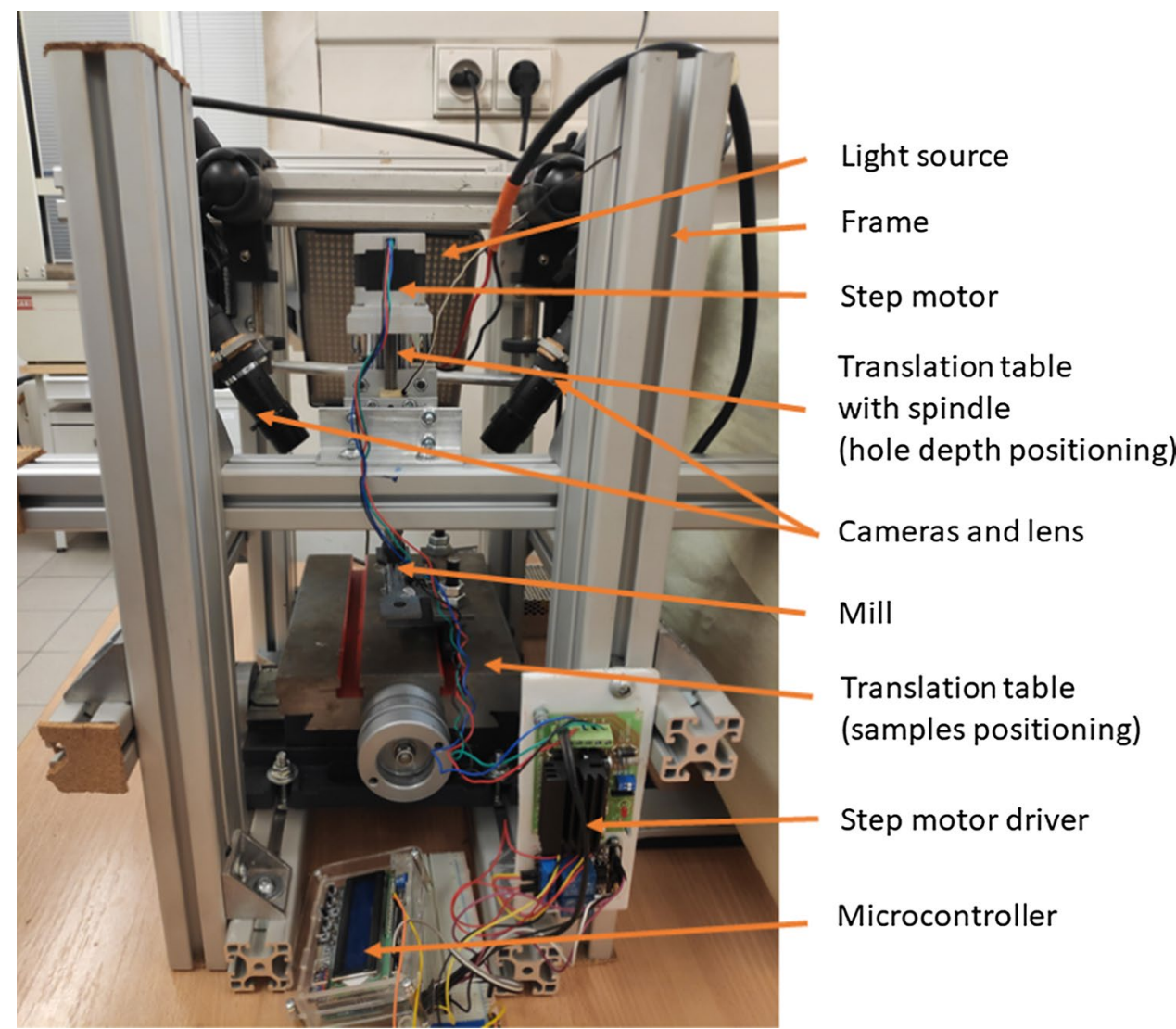

tests on steel samples in annealed state of approximately half of the hardness of materials in question had not revealed additional stresses induced by the drilling process.

The inverse method procedure, based on an iterative Newton-Raphson optimization scheme, was used for calculating the residual stress components. Due to the unavailability of an analytical solution describing the displacement field resulting from a hole drilled in the presence of residual stress components for the case of a blind hole, the arrays of correction terms were determined from FEM modeling and implemented in the equations available for the through-hole case. Polynomials of the fifth order were fitted to the arrays of correction terms determined for a vast range of hole geometries and positions around the hole, making it possible to perform an inverse method calculation, as would be done for the through-hole case for arbitrary data points containing displacements around the holes delivered from the DIC. In addition, the polynomials for a flat surface (plate) and a 16-mm-diameter bar were considered and appropriate corrections made. 
An optimization algorithm utilizing a fitted polynomial for the case of a plate was used to determine the residual stress distribution along a radius of a HE-processed bar of 316 LVM steel (two samples with similar drilling positions, designated as HE1 and HE2) and on the surface of a cylindrical sample of the same chemical composition processed by HPT (two samples with different drilling positions, designated as HPT1 and HPT2). Calculations utilizing the polynomials for the bar were applied in the calculations on the HE-processed bar surface, denoted as HE3. Diagrams of the planned hole locations are presented in Fig. 3. A standard cartesian coordinate system was used, with its $x$-axis parallel to the longitudinal direction of the bar (the same orientation for all holes) in the case of the HE1 and HE2 samples, or parallel to the radial orientation (individually for each hole) in the case of the HPT1 and HPT2 samples. Thus, the $\sigma_{x x}$ and $\sigma_{y y}$ obtained from inverse method calculations denoted the longitudinal and radial stress components for the HE1 and HE2 cases, the longitudinal and hoop (tangential) stress components for the HE3 case, and the radial and hoop stress components for the HPT1 and HPT2 samples, respectively. After the experiments, the exact location and dimensions of the holes were measured using a scanning electron microscope (SEM) images (HPT) or a slide caliper (HE). The results for the bar were supplemented by measurements made on its surface, where polynomial parameters calculated for the convex surface were employed.

Due to the anticipated relatively small displacement magnitude resulting from the material removal relaxation, especially for the 0.5 -mm-diameter holes, in each measurement case, three images of the sample after drilling were recorded for further DIC examination, in order to increase the reliability of the measurements. Moreover, the area from which the displacement field data were used in the residual stress calculation was related in each case to the actual hole diameter. Separate calculations were performed for three cutting radii equal to the hole radius multiplied by factors of two, three, and four. The similarity of the results for the different cut radii confirmed the validity of the calculation method. Consequently, the values of residual stress reported are the averages of nine different calculations.

Furthermore, the residual stress components $\left(\sigma_{x x}, \sigma_{y y}, \sigma_{x y}\right)$, hole center coordinates $\left(x_{0}, y_{0}\right)$ and rigid body movement and rotation $\left(T_{x}, T_{y}, R\right)$ were treated as unknowns, and an optimized set of 8 parameters was delivered during the inverse method calculations coded in the MATLAB scripts. This approach is believed to improve the accuracy of calculations by eliminating the need to determine the hole center manually, as reported in $[23,30]$, and by eliminating the effects of small rigid body displacements incorporated in each DIC measurement-which is difficult to avoid under experimental conditions - on the values of the residual stress components obtained from the results of the optimization procedure.

Analytical equations describing displacement fields near the drilled holes are available only for the through-hole case [31]:

$u_{r}=A\left(\sigma_{x x}+\sigma_{y y}\right)+B\left[\left(\sigma_{x x}-\sigma_{y y}\right) \cos 2 \theta+2 \sigma_{x y} \sin 2 \theta\right]$

$u_{\theta}=C\left[\left(\sigma_{x x}-\sigma_{y y}\right) \sin 2 \theta-2 \sigma_{x y} \cos 2 \theta\right]$

where $A, B, C$ coefficients related to hole geometry [31]:

$A=\frac{r_{0}}{2 E}(1+v) \rho$

$B=\frac{r_{0}}{2 E}\left(4 \rho-(1-v) \rho^{3}\right)$

$C=\frac{r_{0}}{2 E}\left(2(1-v) \rho+(1+v) \rho^{2}\right)$

$\sigma_{x}, \sigma_{y}, \sigma_{x y}$ residual stress components, $(r, \theta)$ polar coordinates

where $r_{0}$ hole radius, $E$ Young's modulus, $v$ Poisson's ratio, $\rho=\frac{r_{0}}{r}, r$ distance from the hole center.

In the case of a blind hole, FEM modeling is required to supply correction coefficients corresponding to that available for through-hole case ( $A, B$ and $C$ ), depending on the hole geometry and the distance from the hole center, namely [31]:

$A^{\prime}=a^{\prime} \frac{r_{0}}{2 E}(1+v)$

$B^{\prime}=b^{\prime} \frac{r_{0}}{2 E}$

$C^{\prime}=c^{\prime} \frac{r_{0}}{2 E}$
Fig. 3 Planned hole positions for the HE1-HE3 (a), HPT1 (b) and HPT2 (c) cases (a)

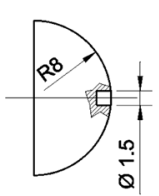

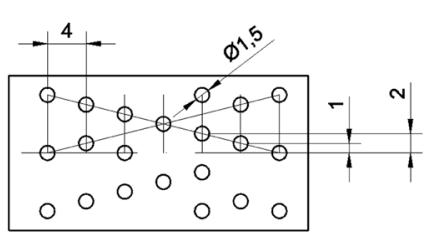

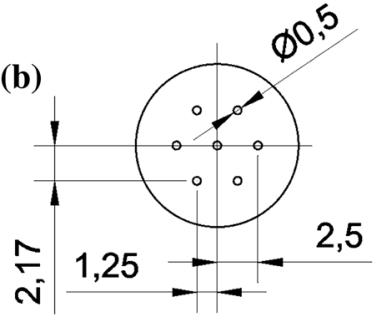

(c)

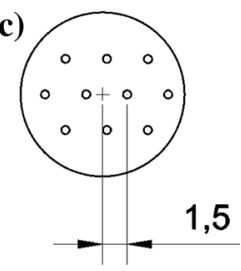


The values of $\sigma_{x}, \sigma_{y}, \sigma_{x y}$ can be calculated if the displacement components in three different locations around the drilled blind hole of the known geometry are delivered, and the corresponding values of three sets of dimensionless $a^{\prime}$, $b^{\prime}$ and $c^{\prime}$ correction parameters are known. Well-established techniques for optical displacement field measurements, such as DIC and ESPI, deliver hundreds or thousands of displacement data points and make it possible to apply an over-deterministic scheme when calculating the residual stress components limiting the influence of erroneous data points on the final results, although correction terms for all the analyzed data point locations are necessary for such calculations.

\subsection{Calculations of correction terms for blind hole case}

If FEM results are available for arbitrary uniaxial loading conditions, nondimensional $a^{\prime}, b^{\prime}$, and $c^{\prime}$ parameters can be determined by using the procedure described in [31]. Those parameters are also valid for complex stress conditions when the hole geometry is similar (i.e., the ratio of hole depthto-hole diameter, $h / d_{0}$, is the same). In a preliminary work [28], correction parameters were determined for fixed hole depths and different distances from the hole center, followed by the fitting of polynomial curves that made it possible to determine residual stress from the inverse method procedure using sets of arbitrary displacement data points (coming from the positions covered by FEM and with size at least equal to the number of unknowns) delivered from full-field DIC measurements. In the other literature examples, only the displacement data from circular paths of a constant distance from the drilled hole center were utilized in calculating residual stress $[23,30]$, and therefore, only a small fraction of the available displacement data were taken into account.

The more general approach presented in this paper involves a determination of arrays of the $a^{\prime}, b^{\prime}$, and $c^{\prime}$ parameters for a wide range of hole depth-to-hole diameters $\left(h / d_{0}\right)$ and hole center-to-hole radius $\left(r / r_{0}\right)$ ratios, followed with appropriate polynomial fitting. This makes it possible to interpolate values, for an arbitrary $h$ and displacement data points, the positions from the range covered by these coefficient arrays. Thus, the iterative, inverse method procedure can be employed, aimed at minimalizing the difference between the displacement field data points obtained from the DIC and their corresponding data points resulting from the analytical model. Similar procedures have been successfully applied in determining stress intensity factors using optical displacement fields method measurements and analytical equations on the displacement fields around a crack tip [32, 33].

Arrays of correction parameters were calculated basing on FEM results for two cases: the surface of a plate of $40 \times 40 \times 4 \mathrm{~mm}$ with a $1-\mathrm{mm}$-diameter hole, and a convex surface of half of a bar of $16 \mathrm{~mm}$ diameter with a $1.5-\mathrm{mm}$ diameter hole. Due to the symmetry of the problem, only $1 / 4$ of the total geometry was taken into account during the calculations. In both cases, uniaxial tensile stress of $500 \mathrm{MPa}$ was simulated. The meshes used in the FEM calculations are presented in Fig. 4. A solid 186 element type and a linear elastic isotropic material model of austenitic steel ( $E=210 \mathrm{GPa}$ and $v=0.29$ ) were used in all the calculations. The element death technique was applied to simulate the removal of material from the drilling locations.

Based on the displacement data from the circular surface, paths positioned at different distances from the hole centers and for simulations of different hole depth arrays of $a^{\prime}, b^{\prime}$ and $c^{\prime}$ parameters were created, followed by the 5 th-degree polynomial fitting.
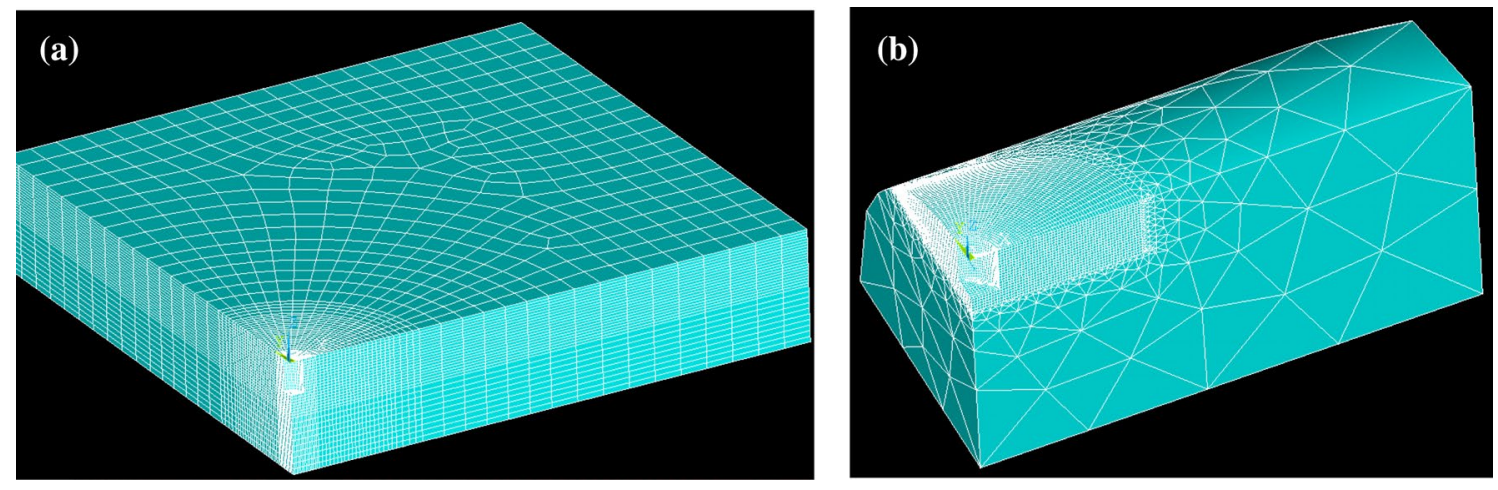

Fig. 4 Meshes used for FEM calculations for a plane and b bar case (1/4 of geometry) 


\section{Results and discussion}

\subsection{Arrays of correction terms}

The arrays of correction terms determined from the FEM modeling are presented in Figs. 5 and 6. Calculations of residual stress components can be performed for arbitrary displacement field data in the range of their coverage, defined by the horizontal axes in the figures. The arrays determined for the flat surface have a universal character and could be used for a vast range of hole depths and diameters. In contrast, the arrays presented in Fig. 6 are valid only for a fixed hole diameter-to-bar diameter ratio, and a change in this relationship would require the recalculation of a new set of correction parameters and new polynomials fitting the data obtained from the new FEM model. Nonetheless, the possibility of this being done, and the ability of 3D DIC to determine displacement fields not only on flat surfaces, enhance the applicability of this procedure for calculating residual stress being applied at least to a bar-shaped surface.

\subsection{Residual stress distribution in HE- and HPT-processed 316 LVM steel}

Exemplary results of the optimization procedure for HE3 case are presented graphically in Fig. 7. The displacement field maps obtained with the use of determined stress tensor components agreed well with those from the DIC measurements for the area limited by $r_{\text {cut }}$, which confirms the reliability of the procedures employed.

The results of the calculations for selected positions in both types of materials tested are presented in Figs. 8, 9 and 10. In the case of the samples processed by HE, the dominant direction of residual stress was coincident with the bar length and changed gradually from tensile near the surface to compressive in the center. Such residual stress distribution in the axial direction is also observed in processing methods similar to HE, such as drawing or open-die extrusion [34]. It should be kept in mind that the minimal distance of $4 \mathrm{~mm}$ initially chosen between the holes was too small to eliminate their affecting each other, and so the results obtained should be treated as mainly qualitative. Further, the FEM analyses showed that the minimal distance should be at least 5 times greater than the hole diameter to reveal more than $90 \%$ of the initial uniaxial residual stress, and this rule was adopted
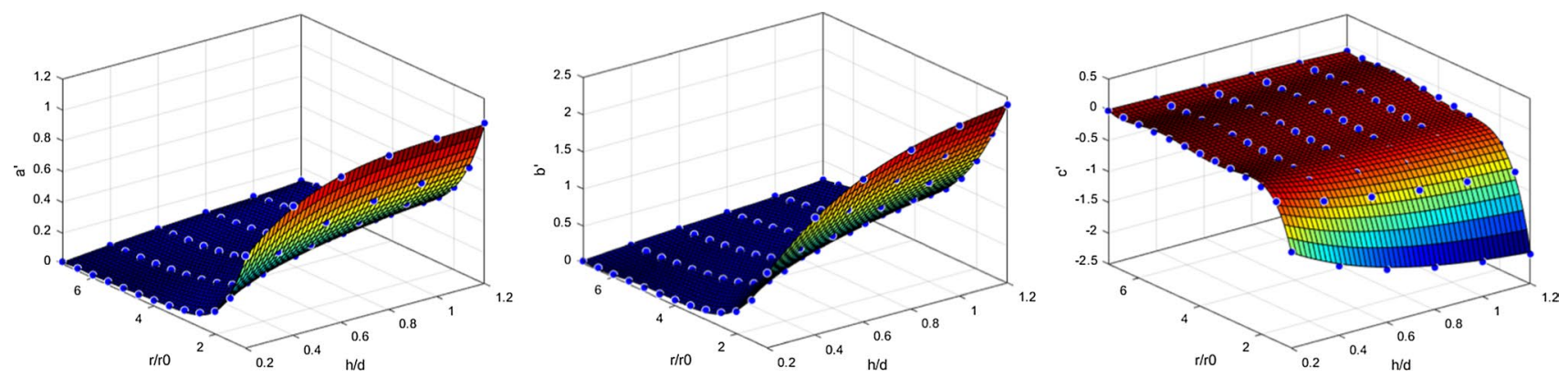

Fig. 5 Arrays of $\mathrm{a}^{\prime}, \mathrm{b}^{\prime}$ and $\mathrm{c}^{\prime}$ correction coefficients (blue dots) obtained from FEM for $40 \times 40 \times 4 \mathrm{~mm}$ plate for a $1.0 \mathrm{~mm}$ hole diameter with fitted polynomial surfaces of the 5 th degree
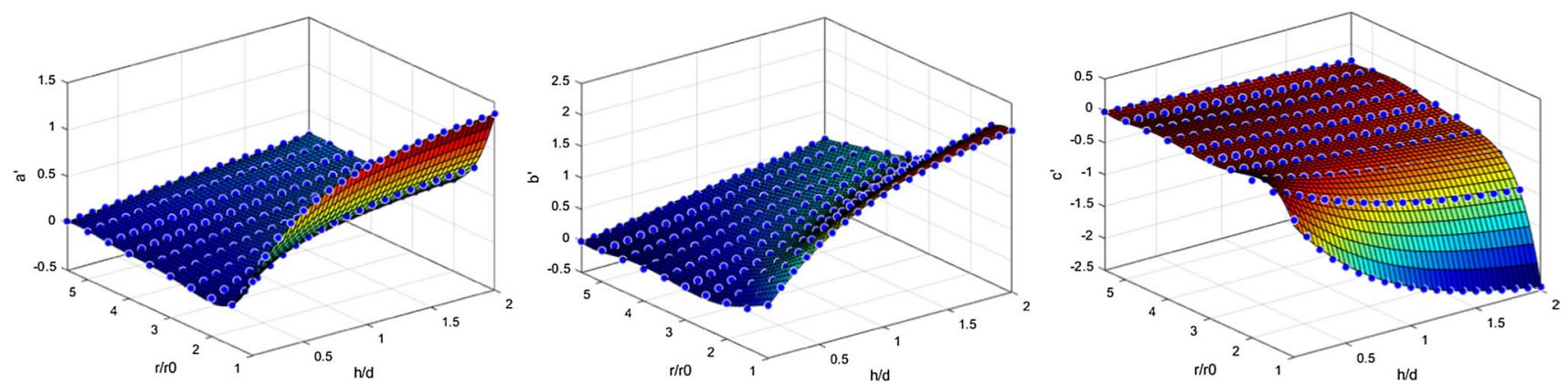

Fig. 6 Arrays of a', $\mathrm{b}^{\prime}$ and $\mathrm{c}^{\prime}$ correction coefficients (blue dots) obtained from FEM for a $16 \mathrm{~mm}$ bar surface for a $1.5 \mathrm{~mm}$ hole diameter with fitted polynomial surfaces of the 5 th degree 
(a)

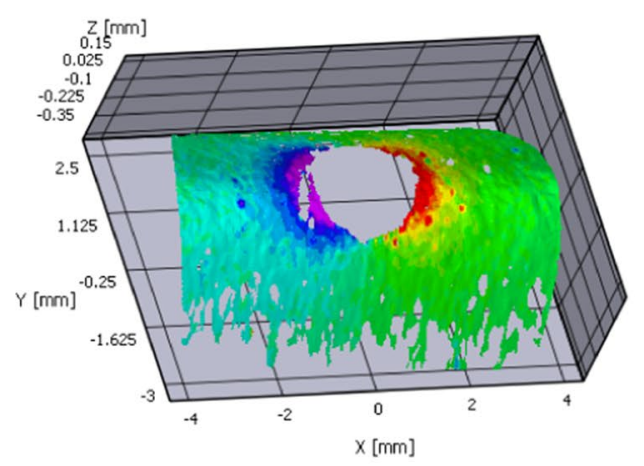

(c)

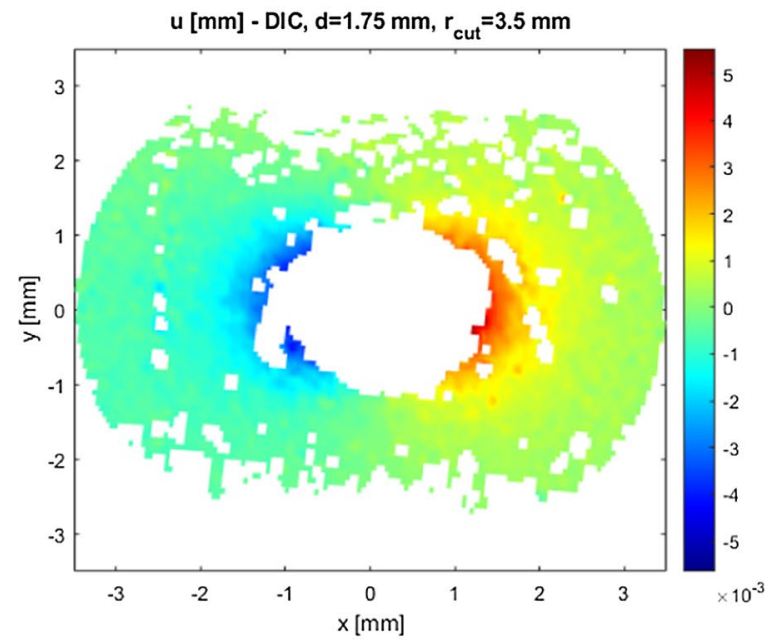

(e)

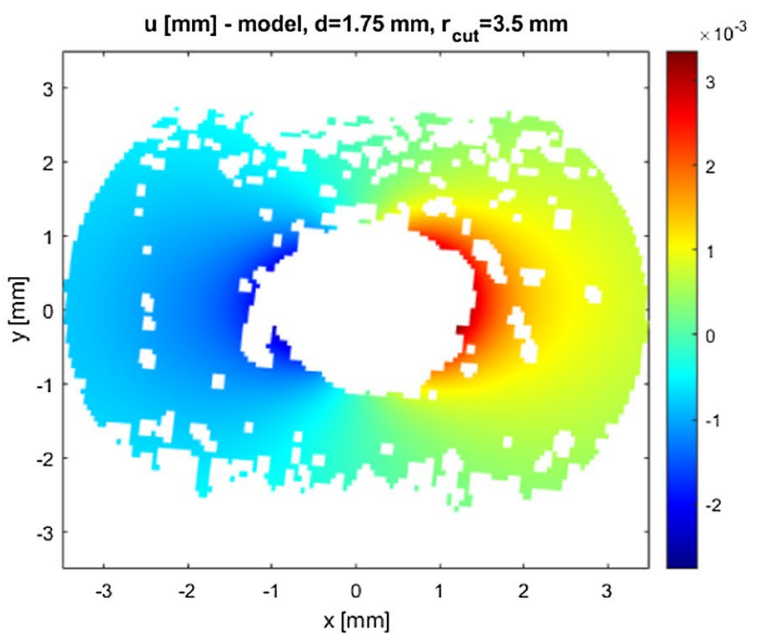

Fig. 7 Exemplary displacement fields around the hole drilled in bar sample: raw data delivered form 3D DIC (a, b), DIC data taken into account in the inverse method calculations $(\mathbf{c}, \mathbf{d})$, and results
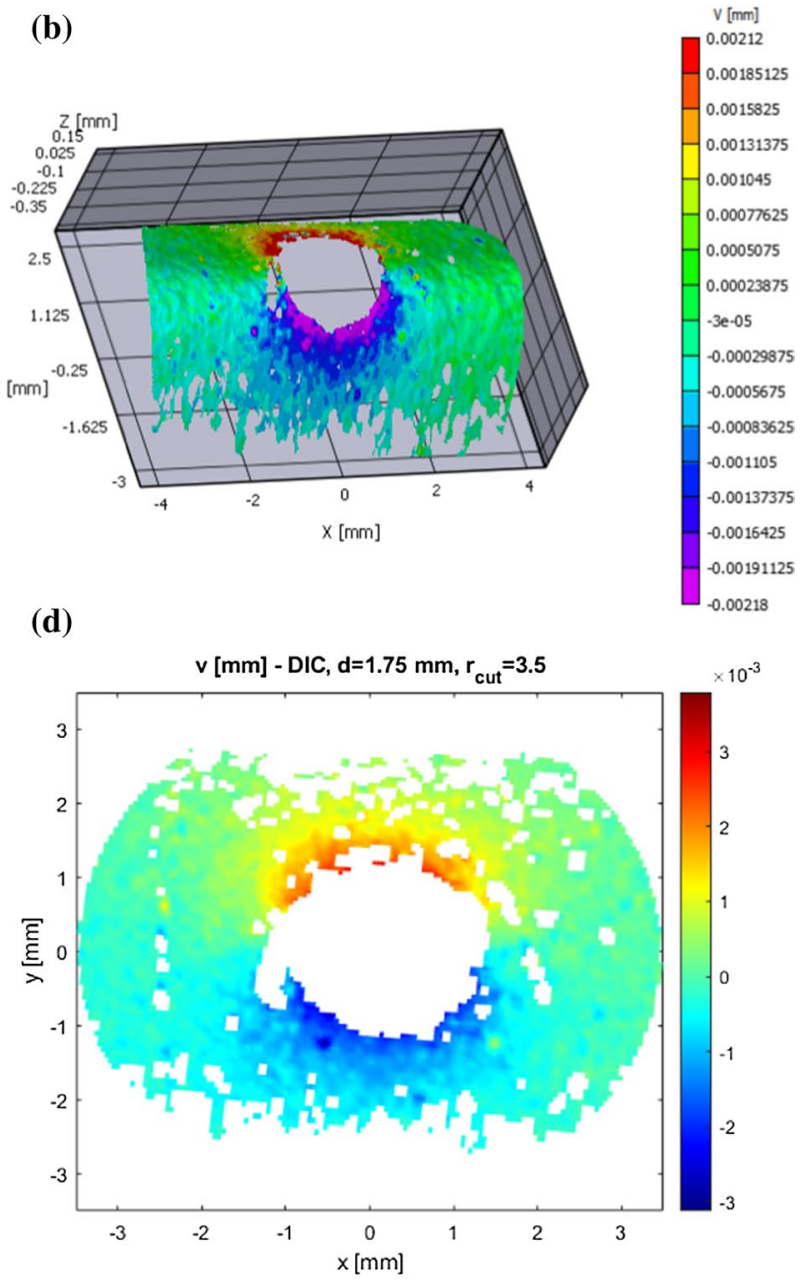

(f)

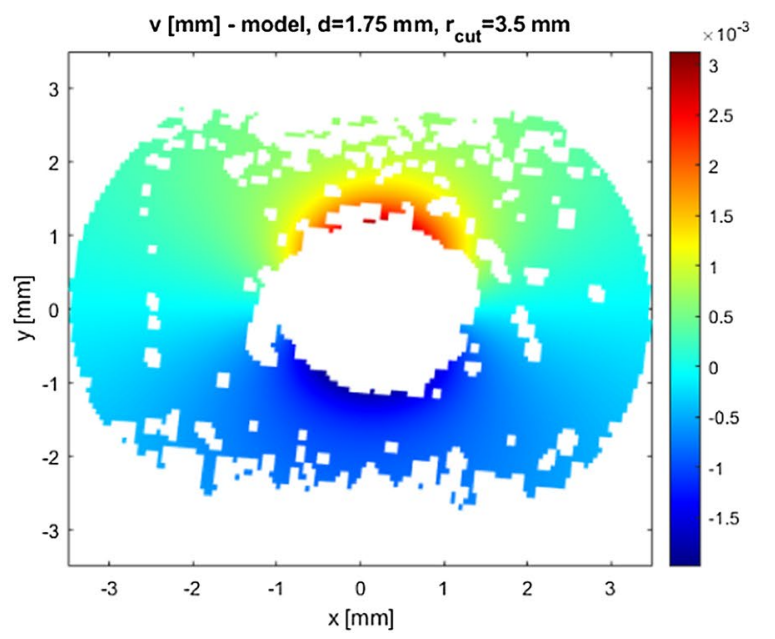

from analytical equations with applied correction terms after inverse method optimization (e, f). Case HE3, hole No. 2, $\sigma_{x x}=492 \mathrm{MPa}$, $\sigma_{y y}=435 \mathrm{MPa}, \sigma_{x y}=7 \mathrm{MPa}$ 
(a)

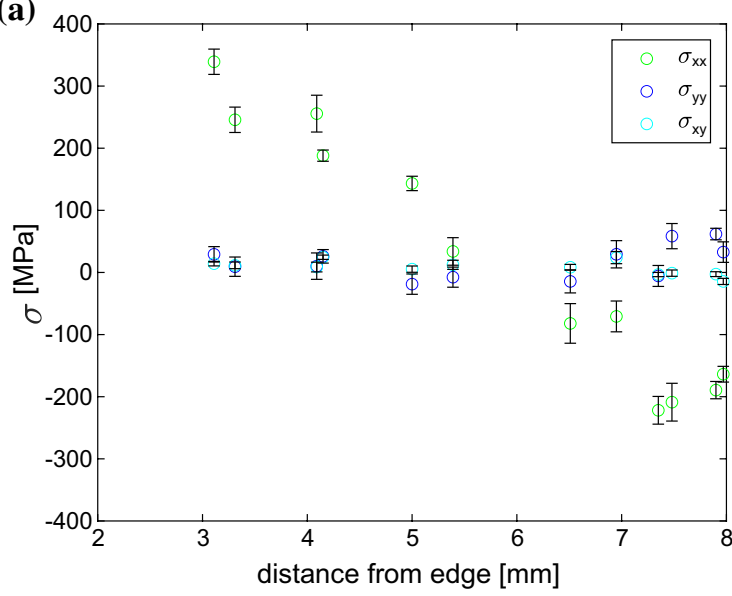

(b)

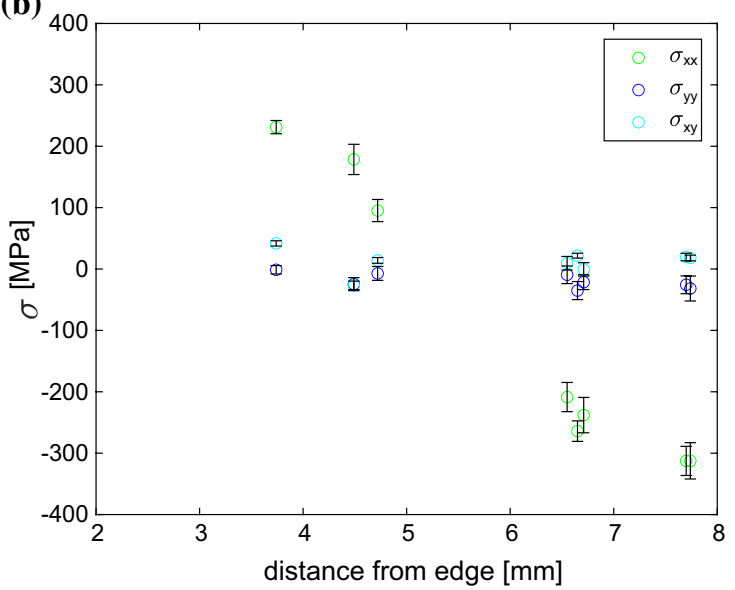

Fig. 8 Profiles of residual stress tensor components for HE1 (a) and HE2 (b) samples (average values from 1, 1.5 and 2 mm hole depths)

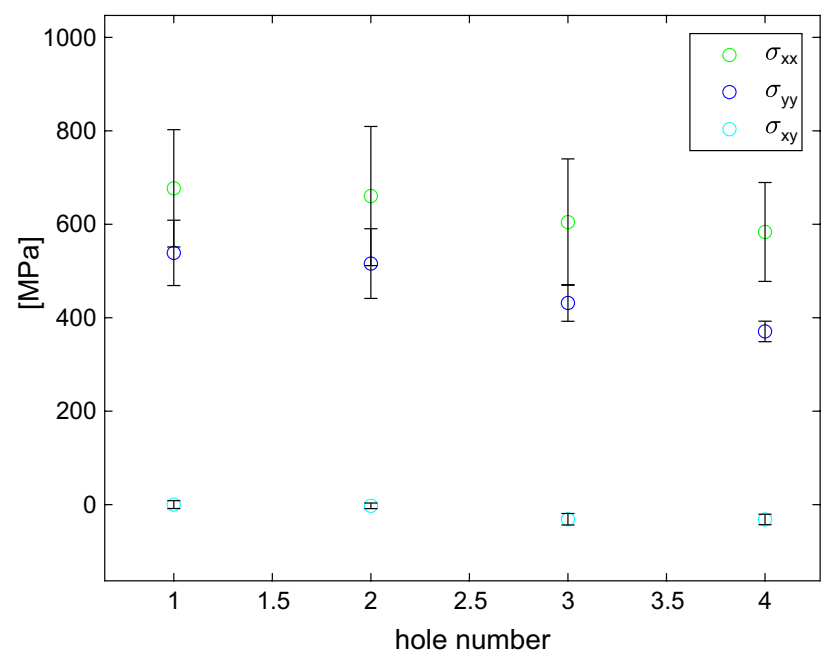

Fig. 9 Results of residual stress calculations for four holes drilled on the HE bar sample surface (average values from 1, 1.5 and $2 \mathrm{~mm}$ hole depths)

for the measurements of the surface of the HE bar and HPT samples.

The calculations for the HE3 case (bar surface) revealed a large tensile longitudinal component and also made it possible to determine the hoop component (unavailable in the case of hole orientation in the HE1 and HE2 testing), of also high positive values. The $\sigma_{x x}$ values decreased with hole depth (resulting in high scattering in the average values presented in Fig. 9, which confirms that stress tends to decrease in the longitudinal direction with increasing distance from the sample edge, as observed in the HE1 and HE2 measurements. The variations of $\sim 200 \mathrm{MPa}$ noted for different drilling positions might have resulted from a non-uniform deformation of the material near the surface.
For all the measurements for the HE-processed material, the shear component determined was close to zero, showing that selected coordinate systems were practically coincident with the principal direction of the stress. In contrast, in the case of HPT, the $\sigma_{x y}$ component was dominant. Moreover, in the case of these measurements, individual coordinate systems were set for each hole, with the $x$-axis coincident with the outward direction of the radius. Therefore, for the sake of clarity, the results are presented in the principal orientation. The revealed $\sigma_{\min }$ and $\sigma_{\max }$ have a symmetrical, funnel-like shape on the plots relating their values to the distance from the sample center (Fig. 10). A narrowing of the funnel is visible at a distance of about $2.5 \mathrm{~mm}$ (1/4 of the sample diameter). The principal angles determined for all measurements excluding those closest to the center have positive values within a range of $\sim 30^{\circ}-75^{\circ}$. The similarity of angles could very well result from the stamp rotation direction, and their scatter from the material's inhomogeneity. A compressive residual stress state was revealed in the center of the HPT-processed disk. Assuming a symmetrical residual stress distribution along the disk diameter with respect to its middle, it was anticipated that very similar values of $\sigma_{\max }$ and $\sigma_{\min }$ would be obtained in the center location, and the results obtained confirmed this hypothesis, even though the true hole location was displaced by $0.2 \mathrm{~mm}$. According to authors' knowledge, this is the first reported result of a residual stress distribution being determined for a $10-\mathrm{mm}$ diameter disk produced by HPT. A similar study of a much larger HPT-processed sample of iron $(30 \mathrm{~mm}$ in diameter and $11 \mathrm{~mm}$ thick), whose residual stress was revealed by means of X-ray diffraction, showed a complex distribution of radial and tangential stress components in the cross section of tested samples, with values of from -100 to $200 \mathrm{MPa}$ [11]. 
(a)

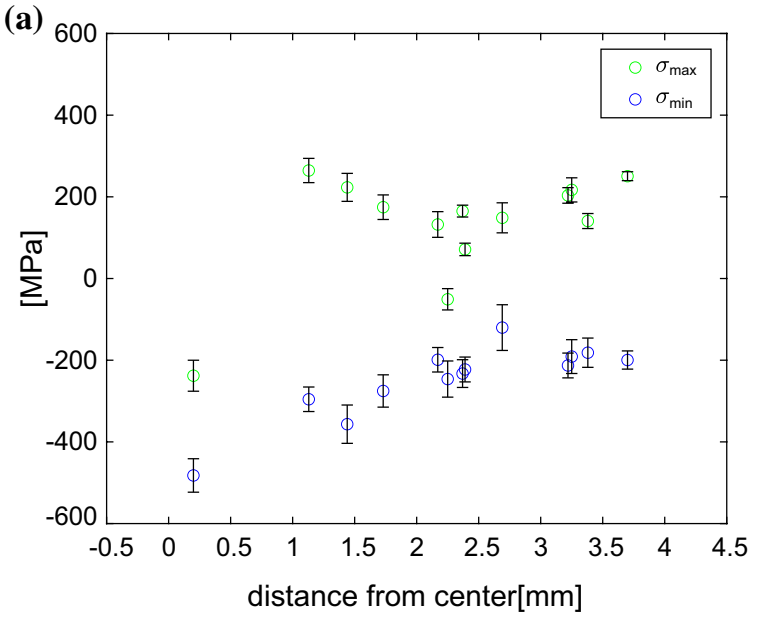

(b)

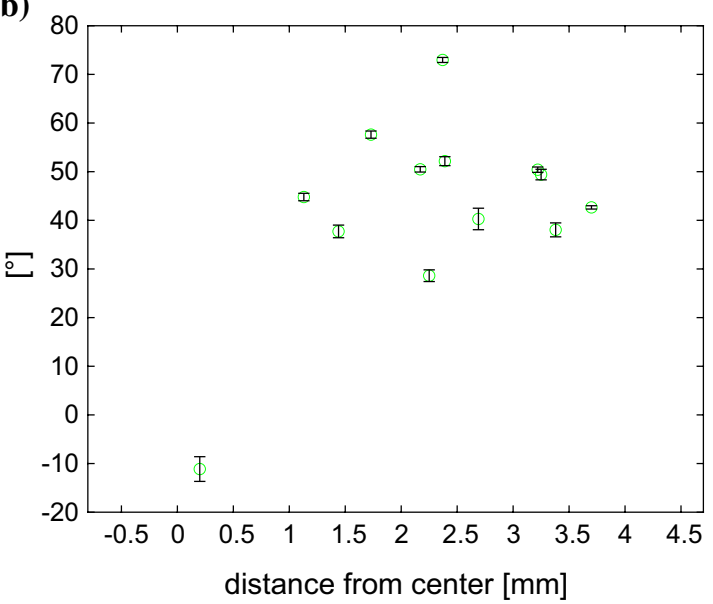

Fig. 10 Profiles of residual stress in the principal direction (a) and principal angles (b) presented collectively for HPT1 and HPT2 samples (0.5-mm-deep holes)

\subsection{Discussion}

HPT results in more profound microstructure refinement than HE. The microstructures also differ in characteristic features, in HPT-processed steel nanograins prevail, whereas in HE-processed steel nano- and ultrafine twins prevail. The fact that HPT leads to a more refined microstructure than $\mathrm{HE}$ is also reflected in microhardness values which is greater for the HPT-processed sample in comparison with HE-processed one. Moreover, as proved in this paper samples differ also in the distribution and values of residual stress. A gradual change in the longitudinal residual stress component from tensile to compressive from the surface to the center was revealed in the HEprocessed bar, while much more complex residual stress states were found in the HPT disk, where the dominant compressive components were observed near the disk shape sample center and a funnel-shaped distribution of principal stresses was revealed oriented at a certain positive angle to the radial direction.

The revealed tensile residual stress near the surface of investigated materials, especially in HE-processed material, is expected to have a negative influence on their application as a structural component in terms of fatigue or stress corrosion performance. Consequently, further processing is required. The methods which are able to successfully introduce compressive residual stress near the surface of austenitic steels at the level that can compensate revealed tensile in tested materials are shot peening (637 MPa) [35] and ultrasonic surface modification (450 MPa) [36]. The question remains open if such methods will be efficient enough in the case of materials with already refined microstructure.

\section{Conclusions}

- A new method of residual stress determination has been developed, employing displacement fields near drilled holes delivered from 3D DIC measurements and an inverse method procedure capable of measurements for a large range of hole geometries and surrounding areas of displacement fields.

- The proposed method delivers information on residual stress distribution basing on much more data in comparison to the traditional one and allows to provide residuals stress profiles with higher resolution disregarding rigid body movement and the need for accurate hole position provision prior testing.

- The method was also enhanced for surfaces that are not flat.

- The robustness of the method was demonstrated for 316 LVM steel samples processed by HE and HPT.

- Residual stresses in HE- and HPT-processed samples differ in their distribution and values due to different levels of microstructure refinement and materials deformation routes.

- The developed methodology is not limited only to SPD processed materials and could be employed with other isotropic materials, especially those available in a limited amount.

Acknowledgements This work was supported by The National Science Center under contract 2016/21/D/ST8/02019. 


\section{Compliance with ethical standards}

Conflict of interest The authors declare that they have no conflict of interest.

Ethical approval This research does not concern experiments involving humans and/or animals and does not require the approval of the ethics committee.

Open Access This article is licensed under a Creative Commons Attribution 4.0 International License, which permits use, sharing, adaptation, distribution and reproduction in any medium or format, as long as you give appropriate credit to the original author(s) and the source, provide a link to the Creative Commons licence, and indicate if changes were made. The images or other third party material in this article are included in the article's Creative Commons licence, unless indicated otherwise in a credit line to the material. If material is not included in the article's Creative Commons licence and your intended use is not permitted by statutory regulation or exceeds the permitted use, you will need to obtain permission directly from the copyright holder. To view a copy of this licence, visit http://creativecommons.org/licenses/by/4.0/.

\section{References}

1. Rossini NS, Dassisti M, Benyounis KY, Olabi AG. Methods of measuring residual stresses in components. Mater Des. 2012. https ://doi.org/10.1016/j.matdes.2011.08.022.

2. Lowe TC, Valiev RZ. The use of severe plastic deformation techniques in grain refinement. JOM. 2004. https://doi.org/10.1007/ s11837-004-0295-z.

3. Valiev RZ, Estrin Y, Horita Z, Langdon TG, Zehetbauer MJ, Zhu YT. Producing bulk ultrafine-grained materials by severe plastic deformation. JOM. 2006. https://doi.org/10.1007/s1183 7-006-0213-7.

4. Valiev RZ, Korznikov AV, Mulyukov RR. Structure and properties of ultrafine-grained materials produced by severe plastic deformation. Mater Sci Eng A. 1993. https://doi.org/10.1016/09215093(93)90717-S

5. Valiev RZ, Islamgaliev RK, Alexandrov IV. Bulk nanostructured materials from severe plastic deformation. Prog Mater Sci. 2000. https://doi.org/10.1016/S0079-6425(99)00007-9.

6. Pakieła Z, Garbacz H, Lewandowska M, Druzycka-Wiencek A, Suś-Ryszkowska M, Zieliński W, Kurzydłowski KJ. Structure and properties of nanomaterials produced by severe plastic deformation. Nukleonika. 2006;51:S19-25.

7. Sedighi M, Mahmoodi M. Residual stresses evaluation in equal channel angular rolled al 5083 by IHD technique: investigation of two calculation methods. Mater Manuf Process. 2013. https://doi. org/10.1080/10426914.2012.700149.

8. Zdunek J, Maj P, Kulczyk M, Mizera J. Texture, residual stresses and mechanical properties analysis in the commercial 1.4462 duplex stainless steel subjected to hydrostatic extrusion. Arch Civ Mech Eng. 2019. https://doi.org/10.1016/j.acme.2018.12.008.

9. Lee HH, Gangwar KD, Park KT, Woo W, Kim HS. Neutron diffraction and finite element analysis of the residual stress distribution of copper processed by equal-channel angular pressing. Mater Sci Eng A. 2017. https://doi.org/10.1016/j.msea.2016.11.094.

10. Geist D, Rentenberger C, Karnthaler HP. Extreme structural inhomogeneities in high-pressure torsion samples along the axial direction. Acta Mater. 2011. https://doi.org/10.1016/j.actam at.2011.04.003.

11. Todt J, Keckes J, Winter G, Staron P, Hohenwarter A. Gradient residual strain and stress distributions in a high pressure torsion deformed iron disk revealed by high energy X-ray diffraction. Scr Mater. 2018. https://doi.org/10.1016/j.scriptamat.2017.11.037.

12. Korznikov AV, Pakieła Z, Kurzydłowski KJ. Influence of longrange ordering on mechanical properties of nanocrystalline Ni3Al. Scr Mater. 2001. https://doi.org/10.1016/S1359-6462(01)01033-8.

13. Mathar J. Determination of initial stresses by measuring the deformation around drilled holes. Trans ASME. 1934;56:249-54.

14. ASTM E837-13a. Standard test method for determining residual stresses by the hole-drilling strain-gage method. Stand. Test Method E837-13a; 2013. https://doi.org/10.1520/e0837-13a.

15. Helm JD. Improved three-dimensional image correlation for surface displacement measurement. Opt Eng. 1996;35:1911. https:// doi.org/10.1117/1.600624.

16. Huang X, Liu Z, Xie H. Recent progress in residual stress measurement techniques. Acta Mech Solida Sin. 2013. https://doi. org/10.1016/S0894-9166(14)60002-1.

17. Hagara M, Trebuňa F, Pástor M, Huňady R, Lengvarský P. Analysis of the aspects of residual stresses quantification performed by 3D DIC combined with standardized hole-drilling method. Meas J Int Meas Confed. 2019. https://doi.org/10.1016/j.measuremen t.2019.01.028.

18. Valiev RZ, Parfenov EV, Raab GI, Semenova IP, Dluhoš L. Bulk nanostructured metals for advanced medical implants and devices. IOP Conf Ser Mater Sci Eng. 2018. https://doi.org/10.1088/1757899x/461/1/012089.

19. Pachla W, Skiba J, Kulczyk M, Przybysz S, Przybysz M, Wróblewska M, Diduszko R, Stepniak R, Bajorek J, Radomski M, Fafara W. Nanostructurization of 316L type austenitic stainless steels by hydrostatic extrusion. Mater Sci Eng A. 2014. https:// doi.org/10.1016/j.msea.2014.07.069.

20. Guo J, Fu H, Pan B, Kang R. Recent progress of residual stress measurement methods: a review. Chin J Aeronaut. 2019. https:// doi.org/10.1016/j.cja.2019.10.010.

21. Giri A, Pandey C, Mahapatra MM, Sharma K, Singh PK. On the estimation of error in measuring the residual stress by strain gauge rosette. Meas J Int Meas Confed. 2015. https://doi.org/10.1016/j. measurement.2014.12.047.

22. Giri A, Pandey C, Mahapatra M. To study the effect of stress magnitude and tool geometry on the calibration coefficients: ring core technique. Proc Inst Mech Eng Part E J Process Mech Eng. 2017;232:095440891773758. https://doi.org/10.1177/0954408917 737585.

23. Nelson DV, Makino A, Schmidt T. Residual stress determination using hole drilling and 3D image correlation. Exp Mech. 2006. https://doi.org/10.1007/s11340-006-5859-0.

24. Kurzydlowski KJ. Hydrostatic extrusion as a method of grain refinement in metallic materials. Mater Sci Forum. 2006. https:// doi.org/10.4028/www.scientific.net/msf.503-504.341.

25. Edalati K, Horita Z. A review on high-pressure torsion (HPT) from 1935 to 1988. Mater Sci Eng A. 2016. https://doi.org/10.1016/j. msea.2015.11.074.

26. Krawczynska AT, Chrominski W, Ura-Binczyk E, Kulczyk M, Lewandowska M. Mechanical properties and corrosion resistance of ultrafine grained austenitic stainless steel processed by hydrostatic extrusion. Mater Des. 2017. https://doi.org/10.1016/j.matde s.2017.09.050.

27. Krawczynska AT, Gierlotka S, Suchecki P, Setman D, AdamczykCieslak B, Lewandowska M, Zehetbauer M. Recrystallization and grain growth of a nano/ultrafine structured austenitic stainless steel during annealing under high hydrostatic pressure. J Mater Sci. 2018. https://doi.org/10.1007/s10853-018-2459-1.

28. Brynk T. Development and validation of 3D DIC based residual stress testing method; 2019. p. 65-70. https://doi.org/10.1007/9783-030-21894-2_13.

29. Brynk T, Romelczyk-Baishya B. Residual stress estimation based on 3D DIC displacement filed measurement around drilled 
holes. Procedia Struct Integr. 2018;13:1267-72. https://doi. org/10.1016/j.prostr.2018.12.259.

30. Lord JD, Penn D, Whitehead P. The application of digital image correlation for measuring residual stress by incremental hole drilling. Appl Mech Mater. 2008. https://doi.org/10.4028/www.scien tific.net/AMM.13-14.65.

31. Makino A, Nelson D. Residual-stress determination by single-axis holographic interferometry and hole drilling-part I: theory. Exp Mech. 1994. https://doi.org/10.1007/BF02328443.

32. Yoneyama S, Ogawa T, Kobayashi Y. Evaluating mixed-mode stress intensity factors from full-field displacement fields obtained by optical methods. Eng Fract Mech. 2007. https://doi. org/10.1016/j.engfracmech.2006.08.004.

33. Brynk T, Laptiev A, Tolochyn O, Pakiela Z. The method of fracture toughness measurement of brittle materials by means of high speed camera and DIC. Comput Mater Sci. 2012;64:221-4. https ://doi.org/10.1016/j.commatsci.2012.05.025.

34. Totten $\mathrm{G}$, Howes M, Inoue T, editors. Handbook of residual stress and deformation of steel. Materials Park: ASM International; 2002.
35. Zhan $\mathrm{K}$, Jiang $\mathrm{CH}$, Ji V. Uniformity of residual stress distribution on the surface of S30432 austenitic stainless steel by different shot peening processes. Mater Lett. 2013. https://doi.org/10.1016/j. matlet.2012.08.147.

36. Ye C, Telang A, Gill AS, Suslov S, Idell Y, Zweiacker K, Wiezorek JMK, Zhou Z, Qian D, Mannava SR, Vasudevan VK. Gradient nanostructure and residual stresses induced by ultrasonic nano-crystal surface modification in 304 austenitic stainless steel for high strength and high ductility. Mater Sci Eng A. 2014. https ://doi.org/10.1016/j.msea.2014.06.114.

Publisher's Note Springer Nature remains neutral with regard to jurisdictional claims in published maps and institutional affiliations. 